\title{
Detection of Aflatoxins in Rice Samples
}

\author{
A. Nisa*, N. Zahra and S. Hina \\ Food and Biotechnology Research Centre Pakistan Council of Scientific and Industrial Research Laboratories \\ Complex, Ferozepur Road, Lahore-54600, Pakistan
}

\begin{abstract}
Aflatoxins are natural contaminants of cereals and other commodities throughout the world. Chronic dietary exposure even to low doses of aflatoxins is a known risk factor for liver cancer and effect protein metabolism and immunity. The study was carried out on a 1029 samples of brown rice, 1561 samples of white rice, 33 samples of broken rice, 13 samples of Sella rice, 52 samples of parboiled rice of export quality from Pakistan during the years 2006-2010 for determination of Aflatoxin B1, B2, G1 and G2 by Thin Layer Chromatography. 341 (33.13\%) samples of white rice, 350 (22.42\%) samples of brown rice, 13 (39.39\%) samples of broken rice, $25(24.27 \%)$ samples of Sella rice and $14(26.92 \%)$ samples of parboiled rice were found contaminated with B1. B2 was detected in $33(3.20 \%)$ samples of white rice, 23 (1.47\%) samples of brown rice and 1(3.03\%) samples of broken rice. While G1 is found in $9(0.8 \%)$ samples of white rice, 57 (3.65\%) samples of brown rice, 1 (1.5\%) samples of parboiled rice. Aflatoxin G2 was absent in all samples.
\end{abstract}

Key Words: Aflatoxin; Mycotoxin; Rice; Thin Layer Chromatography

\section{Introduction:}

Aflatoxins are of great concern with respect to public health due to their potential as powerful hepatotoxic, terotogenic and mutagenic properties causing damages such as hepatitis, hemorrhage, edema, immuno-suppression and hepatic carcinoma. They are produced principally by Aspergillus flavus and Aspergillus parasiticus either before harvest or under post harvest condition (Patterson 2007, Paterson and Lima 2010a-b). Aflatoxins are found as contaminants in various agricultural commodities such as cereals, tree nuts, groundnut and cottonseed. The knowledge that mycotoxins can have serious effects on humans and animals has led many countries to establish maximum tolerated level (MTL) on mycotoxins in foodstuffs and feedstuffs in the last decades to safeguard the health of humans, as well as the economical interests of producers and traders. Currently, worldwide range of limits for AFB1 and total (AFT) are $1-20 \mathrm{ng} / \mathrm{g}$ and $0-5 \mathrm{ng} / \mathrm{g}$, respectively (FAO 2004). Aflatoxin B1 is considered to be one of the most potent hepatotoxins and also human carcinogens. Its toxicity occurs at very low levels and Aflatoxin B1 at concentration of ppb can cause very damaging effects (Bhat and Vasanthi 1999). The presence of aflatoxins or any other toxic residues beyond limits has a serious bearing on the safety and ultimate marketing of food and food products. Human foods are allowed 4-30 ppb aflatoxins depending upon country involved (Henry et al. 1999). Different Factors like moisture content, water activity, contamination level, toxigenic potential of fungal strains, temperature, storage period and nature of substrate influence the production of mycotoxins (Nafeesa et al., 2006).

Pakistan being an agro based country has natural abundance of all agricultural products including all food items. Rice (Oryza sativa Linn.) is the second major cash crop and is also one of the main exports of Pakistan (Javed et al. 2010).

Pakistani rice is famous for its aroma and rich taste worldwide. Aflatoxins (AF) are highly toxic and carcinogenic secondary fungal metabolites and have been detected in various food commodities including cereals. Rice samples collected during 2008-2009 were analyzed for aflatoxin B1 (AFB1), aflatoxin B2 (AFB2), aflatoxin G1 (AFG1) and aflatoxin G2 (AFG2) by thin layer chromatographic (TLC) technique. In total, 40 rice samples were collected and after dividing samples to sub-samples, AF analyses were carried out. AFB1 was detected in 28 samples ( $70 \%$ of the total). The mean of AFB1 was $3.7 \mathrm{ng} / \mathrm{g}$ for all samples. Total AF (AFT) was

*Corresponding author: E-mail: nisaalim64@yahoo.com 
detected in 28 samples ( $70 \%$ of the total). The mean of AFT was $4.9 \mathrm{ng} / \mathrm{g}$ for all samples. AFB1 levels in 20 samples were below the maximum tolerated level (MTL) of AFB1 (2ng/g). Regarding AFT, the mean contamination level $(4.9 \mathrm{ng} / \mathrm{g})$ was higher than the EU maximum permissible level for AFT (4ng/g).

The present study was conducted in Food and Biotechnology Research Centre, PCSIR Laboratories Complex Lahore for the detection of Aflatoxin presence in rice samples.

\section{Materials and Methods}

The present work was carried out at Food and Biotechnology Research Centre of PCSIR Laboratories Complex, Lahore. Rice samples were obtained from different rice export companies of Pakistan during the year 2006-2010. Samples were prepared for Aflatoxin determination by the method described by Begum and Co-workes et al. (1985). Aflatoxins were detected by Romers method (Romer et al. 1976). Estimation of Aflatoxins in toxic extracts was made by comparison with standard technique (AOAC, 2005).

\section{Sampling:}

Since the aflatoxins are not uniformly distributed in commodities, rice samples were likely to have pockets of high aflatoxin concentration; firstly due to highly heterogeneous distribution of aflatoxins and secondly due to marketing in lumps of various sizes. To obtain most representative sample, a suitable sampling plan was adopted. In order to obtain a more representative portion of these samples $500 \mathrm{~g}$ were collected through a sample probe directly in plastic bags piercing jute bags diagonally from 2 to 3 places. They were passed through sample divider and reduced to approximately $200 \mathrm{~g}$ for the purpose of analysis and thus a greater homogeneity of contaminated portion was achieved. Each sample was then thoroughly mixed, grinded and made into fine powder for experimental analysis. The half laboratory sample was grinded through Romer grinding mill and other half was kept for reference.

\section{Extraction}

$50 \mathrm{~g}$ of ground sample was taken into $500 \mathrm{ml}$ conical flask. $25 \mathrm{ml}$ of water, $25 \mathrm{~g}$ diatomaceous earth and 150 $\mathrm{ml}$ chloroform were added and shaked for 30 minutes on wrist action shaker and then filtered. 2nd $50 \mathrm{ml}$ portion $\mathrm{CHCl}_{3}$ was collected and evaporated on a steam bath.

\section{Thin Layer Chromatography}

Immediately spot 5,10 and $10 \mathrm{~mL}$ on TLC plate (Approximately $1.5 \mathrm{~cm}$ from the base). Spot $5 \mathrm{~mL}$ standard on one spot in a duplicate as internal standard. Develop plate with anhydrous ether in developing tank up till half. After development in ether remove the plate from tank and let it dry. Redevelop in same direction in TLC tank with acetone-chloroform (1:9) (v/v). Adjust acetone-chloroform ratio as needed to modify $\mathrm{Rf}$ of aflatoxins. Observe developed plate for presence or absence of spot originating from test solution and with same Rf and appearance as authentic aflatoxin. Observe internal standard for any change in Rf or appearance of aflatoxins caused by extract. Observe only for presence or absence of aflatoxins in test solution spot.

\section{Quantitative determination}

The test solution was evaporated to dryness on steam bath and re-dissolved in calculated volume of benzene-acetonitrile (98:2). Spot successively 3.5, 5.0 and two $6.5 \mu \mathrm{L}$ of test solution. All spots were of approximately same size. On same plate spot 3.5, 5.0 and two $6.5 \mu \mathrm{L}$ of aflatoxins standard, corresponding to aflatoxins observed on preliminary plate or use resolution standard.

\section{Interpretation of the plate}

Examine pattern from test solution spot containing internal standard should be same as or only slightly indifferent from those of respective standard aflatoxins standard spot. test solution pattern were compared with the pattern containing internal standard. Fluorescent spot in test solution thought to be aflatoxins must have $\mathrm{Rf}$ values identical to and color similar to aflatoxins standard spot when unknown spot and internal standard spot are superimposed. Spot from test solution and internal standard combined should be more intense then either test solution or standard alone. Compare the fluorescence intensities of the spots at $\mathrm{Rf}$ of Aflatoxin in the sample with those of the Aflatoxin standard spots and determine which of the sample spot matches one of the standards and record the corresponding aliquot volumes. Interpolate if intensities of test spot is between those of two of standard spot. If spots of the smallest volume of the sample are too intense to match the standards the sample extract should be diluted and 
re-chromatographed. The concentration of the Aflatoxin in the sample in microgram/kilogram is calculated from the formula

Aflatoxins contents $(\mathrm{mg} / \mathrm{kg})=\frac{\mathrm{S} \times \mathrm{Y} \times \mathrm{V}}{\mathrm{W} \times \mathrm{Z}}$

Where,

$\mathrm{S}$--- Volume in $\mathrm{mL}$ of aflatoxin standard of equivalent intensity to $\mathrm{Z}=\mathrm{mL}$ of sample.

$\mathrm{Y}$--- $\quad$ Concentration of aflatoxin standard in $\mathrm{mg} / \mathrm{mL}$

$\mathrm{Z}$--- Volume in $\mathrm{mL}$ of sample extract required to give fluorescence intensity comparable to that of $\mathrm{S}=\mathrm{mL}$ of the Aflatoxin standard.

$\mathrm{V}$--- Volume in $\mathrm{mL}$ of solvents required to dilute final extract

W --- Weight, in grams of original sample contained in final extract

\section{Results and Discussions}

Mycotoxin problems are not specific to the developed or developing world; these are problems that affect the agricultural economies of many countries, interfere or even prevent trade, reduce animal and animal product production and in some countries affect human health. Aflatoxins are amongst the most potent carcinogens, naturally occurring fungal toxic metabolites and cause momentous health risks and acute toxicological effects to human beings as well as animals. Aflatoxin in rice may harm the health to greater extent and if not properly determined; may cause death. Here in this study the aflatoxin in various rice samples was determined and it was found that due to improper storage conditions and many other factors the rice samples were contaminated with aflatoxins.

Table II. Detection of aflatoxins B1, B2, G1 and G2 in white rice samples analysed during the year 2006-2010

\begin{tabular}{cccccc}
\hline Year & $\begin{array}{c}\text { Total } \\
\text { Samples }\end{array}$ & $\begin{array}{c}\text { No. of } \\
\text { samples } \\
\text { B2 }\end{array}$ & $\begin{array}{c}\text { No. of } \\
\text { samples } \\
\text { B1 }\end{array}$ & $\begin{array}{c}\text { No. of } \\
\text { samples } \\
\text { G1 }\end{array}$ & $\begin{array}{c}\text { No. of } \\
\text { samples } \\
\text { G2 }\end{array}$ \\
\hline 2006 & 77 & 56 & 6 & 3 & 0 \\
2007 & 194 & 134 & 12 & 0 & 0 \\
2008 & 195 & 61 & 4 & 0 & 0 \\
2009 & 202 & 42 & 4 & 5 & 0 \\
2010 & 361 & 48 & 7 & 1 & 0 \\
\hline
\end{tabular}

Table I. Total samples \& Aflatoxin contaminated samples of White, brown, Sella, broken and parboiled rice sample analysed during the year 2006-2010

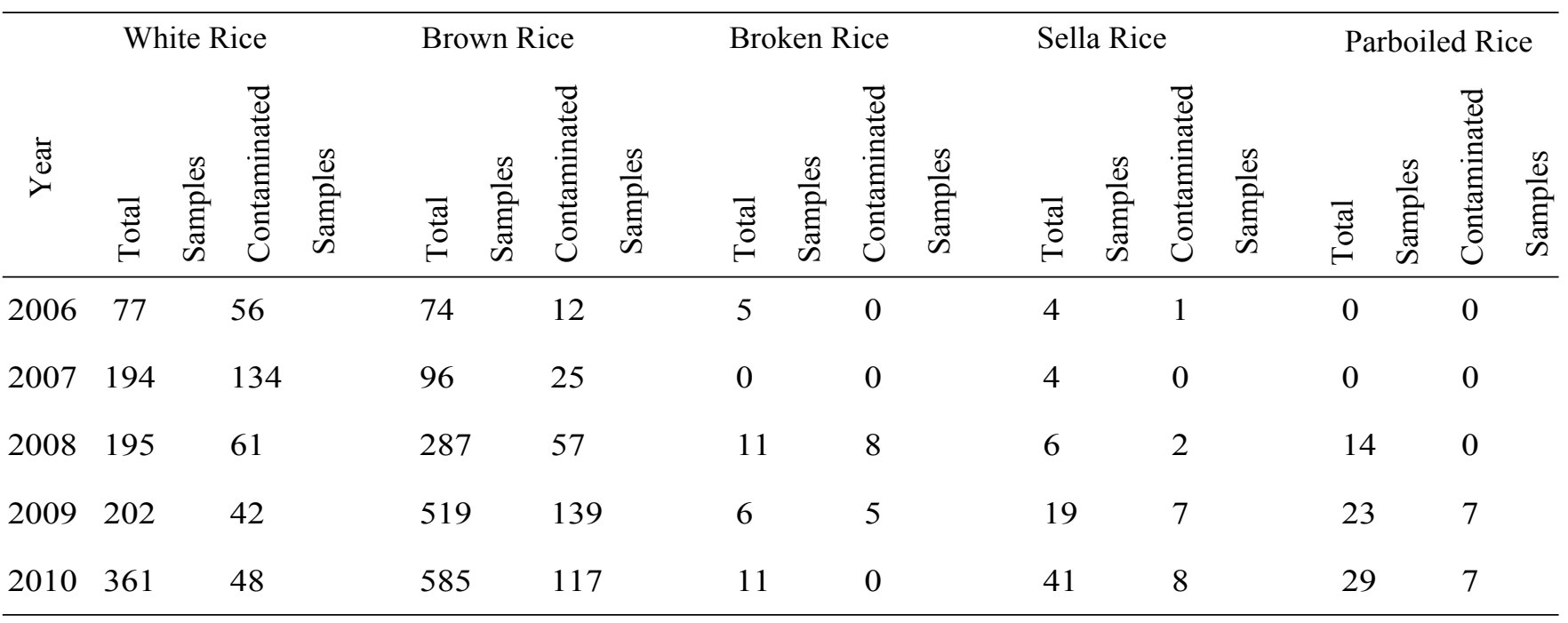

A comprehensive survey was conducted from 2006-2010 to evaluate the level of aflatoxin contamination in selected varieties of export quality rice in Pakistan. Table I. shows total no. of samples and the no. of samples contaminated with aflatoxins. 
Table II. shows samples contaminated with aflatoxin AFB1, aflatoxin AFB2, aflatoxin AFG1 and aflatoxin AFG2 analyzed during the year 2006-2010 in white rice samples. During the study it was observed that 56,134 , $61,42,48$ samples out of $77,194,195,202,361$ total samples showed positive to AFB1 respectively. 6, 12, 4, 4 and 7 samples were found contaminated with AFB2. 3 samples out of 77 in 2006, 5 samples out of 202 in 2009 and 1 out of 361 in 2010 were found contaminated with AFG1. However, there was no contaminated sample with AFG2. In this way 341 (33.13\%) samples of total white rice showed contamination with B1. B1 level in 137 (13.31\%) samples was above permissible limits according to European Union 2010. B2 was detected in $33(3.20 \%)$ samples, while G1 is found in $9(0.8 \%)$ only while G2 was not detected in samples.

Table III. Detection of aflatoxins B1, B2, G1 and G2 in Brown rice samples analysed during the year 2006-2010

\begin{tabular}{cccccc}
\hline Year & $\begin{array}{c}\text { Total } \\
\text { Samples }\end{array}$ & $\begin{array}{c}\text { No. of } \\
\text { samples } \\
\text { B2 }\end{array}$ & $\begin{array}{c}\text { No. of } \\
\text { samples } \\
\text { B1 }\end{array}$ & $\begin{array}{c}\text { No. of } \\
\text { samples } \\
\text { G1 }\end{array}$ & $\begin{array}{c}\text { No. of } \\
\text { samples } \\
\text { G2 }\end{array}$ \\
\hline 2006 & 74 & 12 & 0 & 0 & 0 \\
2007 & 96 & 25 & 2 & 0 & 0 \\
2008 & 287 & 57 & 1 & 1 & 0 \\
2009 & 519 & 139 & 13 & 21 & 0 \\
2010 & 585 & 117 & 7 & 35 & 0 \\
\hline
\end{tabular}

The data indicated in the Table III. shows the presence of aflatoxins in brown rice samples. All samples were found highly contaminated with Aflatoxins. Among 74, $96,287,519$ and 585 samples analyzed during the years 2006-2010: 12, 25, 57, 139 and 117 samples showed contamination with AFB1 respectively. 2 out of 96 in 2007,1 out of 287 in 2008,13 out of 519 in 2009,7 out of 585 samples were contaminated with AFB2. 1 out of 287,21 out of 519 and 35 out of 585 samples were contaminated with AFG1 and there was no sample with AFG2. In this way $350(22.42 \%)$ of brown rice was found contaminated with B1. B1 levels in $99(6.34 \%)$ samples of brown rice showed contamination above permissible limits. B2 was detected in $23(1.47 \%)$ samples, while G1 is found in 57 (3.65\%) samples. All the samples showed absence of G2.

Among 5, 11, 6 and 11 samples analyzed during the years 2006, 2008-2010 respectively only 13 samples showed contamination with aflatoxins (Table 4). 8

Table IV. Showing the Intensity of aflatoxins B1, B2, G1 and G2 broken rice samples analysed during the year 2006-2010

\begin{tabular}{cccccc}
\hline Year & $\begin{array}{c}\text { Total } \\
\text { Samples }\end{array}$ & $\begin{array}{c}\text { No. of } \\
\text { samples } \\
\text { B2 }\end{array}$ & $\begin{array}{c}\text { No. of } \\
\text { samples } \\
\text { B1 }\end{array}$ & $\begin{array}{c}\text { No. of } \\
\text { samples } \\
\text { G1 }\end{array}$ & $\begin{array}{c}\text { No. of } \\
\text { samples } \\
\text { G2 }\end{array}$ \\
\hline 2006 & 5 & 0 & 0 & 0 & 0 \\
2007 & 0 & 0 & 0 & 0 & 0 \\
2008 & 11 & 8 & 1 & 0 & 0 \\
2009 & 6 & 5 & 0 & 0 & 0 \\
2010 & 11 & 0 & 0 & 0 & 0 \\
\hline
\end{tabular}

samples were found contaminated with AFB1 and 1 to AFB2 in 2008. 13 (39.39\%) samples of broken rice were contaminated with B1. B1 levels in $3(6.0 \%)$ samples of broken rice showed contamination above permissible limits. B2 was detected in $1(3.03 \%)$ of total samples. All the samples showed absence of G1 and G2 respectively.

Analytical data shown in Table 5 shows the presence of aflatoxins in Sella rice. The samples analyzed in the year 2007 were not contaminated with Aflatoxins. 1out of 4

Table V. Detection of aflatoxins B1, B2, G1 and G2 Sella rice samples analysed during the year 2006-2010

\begin{tabular}{cccccc}
\hline Year & $\begin{array}{c}\text { Total } \\
\text { Samples }\end{array}$ & $\begin{array}{c}\text { No. of } \\
\text { samples } \\
\text { B2 }\end{array}$ & $\begin{array}{c}\text { No. of } \\
\text { samples } \\
\text { B1 }\end{array}$ & $\begin{array}{c}\text { No. of } \\
\text { samples } \\
\text { G1 }\end{array}$ & $\begin{array}{c}\text { No. of } \\
\text { samples } \\
\text { G2 }\end{array}$ \\
\hline 2006 & 4 & 1 & 0 & 0 & 0 \\
2007 & 4 & 0 & 0 & 0 & 0 \\
2008 & 6 & 2 & 0 & 0 & 0 \\
2009 & 19 & 7 & 0 & 0 & 0 \\
2010 & 41 & 8 & 0 & 0 & 0 \\
\hline
\end{tabular}


in 2006, 2 out of 6 in 2008, 7 out of 19 in 2009 and 8 out of 41 in 2010 samples showed contamination with aflatoxins B1. There was no contaminated sample with AFB2, AFG1 and AFG2. In this way $25(24.27 \%)$ samples of Sella rice were found contaminated with B1. B1 levels in samples $4(3.8 \%)$ samples showed contamination above permissible limits.

Table VI. Showing the Intensity of aflatoxins B1, B2, G1 and G2 parboiled rice samples analysed during the year 2006-2010

\begin{tabular}{cccccc}
\hline Year & $\begin{array}{c}\text { Total } \\
\text { Samples }\end{array}$ & $\begin{array}{c}\text { No. of } \\
\text { samples } \\
\text { B2 }\end{array}$ & $\begin{array}{c}\text { No. of } \\
\text { samples } \\
\text { B1 }\end{array}$ & $\begin{array}{c}\text { No. of } \\
\text { samples } \\
\text { G1 }\end{array}$ & $\begin{array}{c}\text { No. of } \\
\text { samples } \\
\text { G2 }\end{array}$ \\
\hline 2006 & 0 & 0 & 0 & 0 & 0 \\
2007 & 0 & 0 & 0 & 0 & 0 \\
2008 & 14 & 0 & 0 & 0 & 0 \\
2009 & 23 & 7 & 0 & 1 & 0 \\
2010 & 29 & 7 & 0 & 0 & 0 \\
\hline
\end{tabular}

Table VI. shows the presence of aflatoxins in parboiled rice. Among 14, 23, 29 samples analyzed during the years 2008, 2009 and 2010, only 7 out of 23 in 2009 and 7 out of 29 in 2010 were found contaminated with aflatoxins B1. There was no contaminated sample with AFB2 and AFG2. Only 1 sample out of 23 samples was found contaminated with AFG1 during 2009.

\section{Conclusion}

Our investigation demonstrates that rice market represents a significant source of exposure to aflatoxin. Rice samples collected from different companies and clients during the year 2006-2010 only white and brown rice samples showed highest AFB1 contamination i.e. 341 (33.13\% of total) and $350(22.42 \%$ of total) respectively. B1 level in 137 (13.31\%) samples of white rice, $99(6.34 \%)$ samples of brown rice were found above permissible limit which should not more than 2 ppb for AFB1 and total 4 ppb for total aflatoxins. The presence of aflatoxins beyond limits has a serious bearing on the safety and ultimately can reduce the quality and Marketability of food products. Mycotoxins are a major cause of deterioration and spoilage in stored crops. So it is necessary to monitor and control contamination of these commodities from aflatoxins in both domestic and international trade. The extra care should be employed both in post and pre harvest measures to reduce the risk of aflatoxin contamination. Contamination can originate in the field and increase dramatically during grain Storage. The Proper management of the crop, careful handling and proper storage of the grain are very critical in preventing aflatoxin contamination.

\section{References}

AOAC (2005), Official Methods of Analysis, Association of Official Analytical Chemists. Washington DC, USA.

Begum N., Adil R., Shah F. H. (1985), Contamination of groundnuts with Aflatoxins. Pakistan Journal of Medical Research, 24: 129-31.

Bhat R. and Vasanthi S. (1999), Mycotoxin Contamination of Foods and Feeds: Overview, Occurrence and Economic Impact on Food availability, Trade, Exposure of Farm Animals and Related Economic Losses, Third Joint FAO/WHO/UNEP.

F. A. O. (2004), World wide regulations for mycotoxins in food and feed in 2003. Food and Agriculture Organization of the United Nations, Food and Nutrition Paper, No. 81, Rome.

Henry S. H., Bosch F. X., Troxell T. C. and Bolger P. M. (1999), Public health: Reducing liver cancer-global control of aflatoxin, Science, 286: 2453-2454.

Javed S. H., Naveed S., Ramzan N., Feroze N. and Zafar M. (2010), Journal of the Chemical Society of Pakistan, 32: 78.

Nafeesa Q. H. and Salma K. (2006), Pakistan Journal of Food Science, 16: 44.

Paterson R. R. M. (2007), Aflatoxins contamination in chili samples from Pakistan. Food Control, 18: 817-820. 
Paterson R. R. M. and Lima N. (2010a), How will climate change affect mycotoxins in food? Food Research, 43: 1902-1914.

Paterson, R. R. M. and N. Lima (2010b), The Weaponisation of Mycotoxins. In: Varma, A. and M.K. Rai (eds.), Mycotoxins in Food, Feed and Bioweapons, Springer Verlag, pp. 367-384.
Romer T. R. (1976), A screening method for Aflatoxins in mixed feed and other agriculture commodities. Journal of the Association of Official Analytical Chemists, 59: 110-117.

Received: 17 December2013; Revised: 7 April 2014; Accepted: 25 August 2014. 